\title{
The process of health visiting and its contribution to parental support in the Starting Well demonstration project
}

\author{
Jean McIntosh BSc(Hons) PhD RGN OBE FRCN ${ }^{1}$ and Jon Shute MA(Hons) MSc ${ }^{2}$ \\ ${ }^{1}$ Caledonian Nursing and Midwifery Research Centre, School of Nursing, Midwifery and Community Health, Glasgow \\ Caledonian University, Glasgow and ${ }^{2}$ School of Law, University of Manchester, Manchester, UK
}

\author{
Correspondence \\ Jean McIntosh \\ Professor of Community Nursing Research \\ School of Nursing, Midwifery and \\ Community Health \\ Glasgow Caledonian University \\ 70 Cowcaddens Road \\ Glasgow G4 0BA \\ UK \\ E-mail: J.Mclntosh@gcal.ac.uk
}

\begin{abstract}
Significant resources are being directed at interventions designed to attenuate the effects of deprivation on children's health and development. The Starting Well demonstration project, established in two deprived areas within a Scottish city, aimed to show that a programme of planned activities to support families could improve child health. The project was subject to a main quantitative evaluation and several additional qualitative and mixed-method evaluations. The present paper draws on findings from one of the qualitative studies that sought to gain insight into how interventions provided by health visitors were operationalised and how they were perceived by parents. The particular focus of this paper is how the process of health visiting resulted in parents' perceptions of being supported. A longitudinal design captured variation in work undertaken by health visitors and temporal changes in maternal experiences of child rearing. Semi-structured interviews were conducted with 20 mothers and their health visitors at two time points, i.e. when infants were 3-4 and 9-10 months old. Sampling was 'purposive', and included first-time and experienced mothers. The findings reported here are based on 59 interviews carried out during 2002 and 2003. The analysis involved a thematic approach focused on programme implementation, and participant perceptions about process and benefit. Parental perceptions of being supported were exemplified by increased confidence in infant care, reduced anxiety regarding infant care needs, increases in knowledge and sense of personal competence in parenting practices, reduced isolation, and advocacy for those experiencing problems. A selection of the interactional processes that resulted in these forms of perceived support are reported, including methods of providing information, cautious and tactful questioning of maternal decision-making, and encouragement of successful parenting practice. The implications for practice, service delivery and targeting at the individual level are noted.
\end{abstract}

Keywords: demonstration project, health visiting practice, intensive visiting, support

Accepted for publication 14 August 2006

\section{Introduction}

The damaging effect of poverty on young children has become a concern of governments worldwide (Gomby et al. 1993, Ramey \& Ramey 1993, Scottish Office 1999,
Vimpani 2002, Department for Education and Skills 2003, Leggat 2004, Mackenbach \& Stronks 2004). Significant resources have been directed at interventions designed to attenuate or reverse the negative effects of deprivation on children's health and development 
(Olds \& Kitzman 1993, Armstrong et al. 1999). The design of these interventions has usually been informed by evidence of the link between environment, socioeconomic circumstances, and the nature of parenting and health (Brooks-Gunn \& Duncan 1997, Graham \& Power 2004). Therefore, it is unsurprising that the underpinning of such interventions is theoretically eclectic, with programme design being founded generally upon an integration of epidemiology with theories of child development, behavioural change, self-efficacy, human ecology and human attachment (Olds et al. 1999). Interventions are directed at modifying specific risk factors for the health of mothers and children; for example, poor birth outcomes, child abuse and postnatal depression. Thus, interventions are complex, multifaceted and targeted at groups living in areas of known deprivation.

These interventions have a number of common features, but domiciliary person-to-person support for mothers of young children is an almost universal component (Gomby et al. 1999, Olds et al. 2004). This takes the form of interventions directed at raising mothers' awareness of and encouraging their adoption of measures to benefit their own and their family's health, such as increasing self-efficacy, developing responsive and confident parenting practice, and exploiting social networks (Olds et al. 1999, Olds et al. 2004). In the UK, Scandinavia and the USA, this support is delivered by health visitors or their equivalent (Kamerman \& Kahn 1993). Intensive visiting by professionals is costly and programmes have accordingly been the subject of close scrutiny in terms of their outcomes. However, evaluations of complex interventions pose a number of challenges, particularly when they also include input in the form of community-based resources (Elkan et al. 2000). Evaluation of programmes aimed at long-term goals such as improving the health and life chances of young children is particularly challenging. As in many interventions, the use of randomised controlled trials has been favoured as the gold standard for providing evidence on outcome (Sweet \& Appelbaum 2004).

The measures used within these trials are numerous, wide-ranging, collected at intervals, and focus on intervention components that influence risk factors for poor child health and development (Gomby et al. 1999, McNaughton 2004). Examples of the measures used include assessment of children's cognitive development, immunisation rates, attendance at emergency departments, instances of verified child abuse, assessment of parenting practice and the quality of the home environment (Olds \& Kitzman 1993, Kitzman et al. 1997, Gomby et al. 1999, St Pierre \& Layzer 1999, Olds et al. 2004, McNaughton 2004).

These quantitative measures provide evidence of a range of programme outcomes that have generally been positive, demonstrating that there are health and developmental benefits of home visiting (Olds et al. 2004). However, positive changes have not been universally achieved, applying in some cases only to specific subgroups within the sample population. In other instances, the beneficial effects of the interventions were only modest (Gomby et al. 1999, McNaughton 2004, Olds et al. 2004). The reasons for these variable outcomes may include differences in programme design, inconsistencies in the delivery of the programme, or methodological weaknesses in evaluations. With regard to programme design and programme delivery, it must be acknowledged that however, methodically interventions have been formulated, and despite vigorous efforts to ensure consistency in delivery, there are a number of ways in which implementation can be disrupted. For example, there is wide variation in visit intensity (Gomby et al. 1993), some elements of the programme may fail to provide guidance that is specific enough (Olds et al. 1998), there may be delays in implementation because of the need to support families through a period of crisis (St Pierre \& Layzer 1999) and the intervention may be adapted to different circumstances (Powell 1993).

In addition, the crucial medium through which the programme is implemented is the relationship that the health visitor forms with mothers and other family members. A number of researchers have provided a body of evidence that identifies reasons why this relationship is so central. Chalmers \& Luker (1991) identified it as enabling continued access and input, while Jack and colleagues pointed to maternal ambivalence regarding home visiting and the importance of a relationship of trust to disclosure of sensitive topics (Jack et al. 2002). In her study of how health visitors adapt their approach to different circumstances, Cowley $(1995$, p. 282) showed how 'deep empathy, caring and support' were required for successful health visiting interventions. As Powell (1993, p. 23) has also argued, 'the nature of the relationship between visitor and parent and the way in which the programme worker handles the visit combine to create qualitatively different experiences for parent and child'. In summary, an empathetic health visitor/parent relationship rather than a didactic relationship may make the difference between a positive and a neutral/ negative response to the intervention. However, while authors agree that this is a key aspect of home visiting, it is an area that has been neglected in international research regarding the specific approaches that are beneficial for family health outcomes. Therefore, while quantitative evaluations of outcome are essential, it is equally important to investigate the process of delivery at the person-to-person level (Elkan et al. 2000). It is only through scrutiny of process, and the resulting parental perceptions of benefit, that the strengths and weaknesses 
of programme design can be better understood. In particular, it is important to identify whether and in what ways the microprocesses of practitioner/parent interaction embody the theoretical underpinnings of the programme. This has also not been evident in much of the published work to date (Ciliska et al. 1996, Elkan et al. 2000). If such 'process evidence' could be developed, it could be used to inform practitioner education and professional development.

The opportunity to explore 'health visiting process' within a programme of interventions loosely based on ecological theory was presented through the present authors' association with a large-scale evaluation of the Starting Well demonstration project based in one Scottish city.

\section{The Starting Well demonstration project}

The Starting Well demonstration project was established in November 2000 in response to Government plans to improve the health of the Scottish population, detailed in the White Paper Towards a Healthier Scotland (Scottish Office 1999). The project aims were to 'demonstrate that child health can be improved by a programme of activities to support families, coupled with access to enhanced community-based resources for parents and their children' (Glasgow Healthy City Partnership 1999) (for details, see Box 1).

The home-visiting component of the project was structured, and comprised an 'intensive' visiting schedule during the child's first 3 years of life (for details, see Box 2), the requirement to complete a Family Health Plan (summary in Box 3), the aim to engage parents in

\section{Box 1 Main features of the Starting Well demonstration project}

- Guiding principles included empowerment of and active participation by families, and efforts directed at addressing problems of social exclusion

- Adoption of an ecological approach, recognising the material, social, behavioural and psychological influences on maternal and child health

- Two main components were intensive home support provided by skill-mix teams, led by health visitors, and access to a strengthened network of community resources

- Developed from a substantial evidence base from the USA and the UK of the value to health and well-being of intensive home support

- Duration of the project: 3 years in the first instance

- Starting Well health visitors were supported by a health visitor coordinator at each of the two sites

- A set of evidence-based practice guides was developed by the health visitors to ensure consistent messages to families on a range of subject areas
Box 2 Intensive visiting schedule by Starting Well health visitors

- Weekly for 2 months

- Fortnightly from 2 to 6 months

- Monthly from 6 to 12 months

- At any time and after one year, according to need

Box 3 Family Health Plan summary

- Records family health needs

- Identifies activities aimed at addressing needs

- Goals for action are jointly agreed between the health visitor and the mother

- Records outcome of activities, including referrals and significant events

Box 4 Triple P Parenting Programme summary of aims and content

- Multilevel approach with a range of delivery modalities

- Empirically validated

- Aims to increase self-efficacy and confidence in parenting

- Provides strategies for a range of parenting activities

- Provides practitioner and parent resources

goal-setting directed at improving their own and their infants' health, a staged programme of topics, and the use of the Triple P parenting programme (outlined in Box 4) (Sanders \& Woolley 2005).

While the design of these activities was strongly influenced by the work of (Olds \& Kitzman 1993), the project proposal contained few if any explicit references to the range of theories underpinning Olds et al.'s (1998) model. Possibly as a consequence of this, the training provided for the Starting Well health visitors lacked a strong theoretical focus. Additionally, in order to avoid stigma, a universal service was provided in two targeted deprived communities and Starting Well health visitors had reduced caseloads to facilitate the intensive nature of the work. At a later point, skill mix was to be introduced with the appointment of health support workers and nursery nurses to work collaboratively with Starting Well health visitors.

\section{The evaluation of Starting Well}

An external evaluation of the Starting Well demonstration project was commissioned by the Scottish Executive and comprised three main strands:

- a theory of change element to explore stakeholders' perspectives; 
- a quasi-experimental component focused on outcomes; and

- qualitative studies of the processes involved in programme implementation (Mckenzie et al. 2004).

The quasi-experimental component employed a range of measures and included an intervention and a comparison group (Shute \& Judge 2005). The measures included, inter alia, quality of the home environment, maternal depressive symptoms, child dental registration rates, and measures of client satisfaction.

The qualitative components of the evaluation sought to gain insight into different aspects of programme delivery, how the programme was operationalised 'on the ground' and how it was experienced by parents. The present paper draws on data from one of the qualitative studies that explored the work undertaken by health visitors with mothers and their infants, and focuses on how the process of health visiting resulted in parents' perceptions of being supported. Other components of the evaluation are reported elsewhere (Mckenzie et al. 2004, Shute \& Judge 2005). Given the complexity of the intervention that health visitors were required to offer and the fact that it comprised key elements that did not necessarily form part of 'routine' practice, it was considered important to investigate both professional and client experiences of and responses to the programme.

\section{Design and methods used to explore the process of Starting Well}

A longitudinal design was selected to capture the variation in work undertaken by the health visitors and the changes in maternal experiences of child rearing over time. During the first year of the programme, two semistructured in-depth interviews were conducted with a sample of health visitors and parents. They were undertaken by the present authors, who are both experienced interviewers. The interviews took place when infants were between 3 and 4 months, and 9 and 10 months old. These time points were chosen for four principal reasons: to allow mothers to recover from the birth; to avoid researcher intrusion during the period of intensive visiting; to ensure that health-visiting intervention had sufficient time to have some impact on parenting practice; and to capture experience of reduced visiting.

A sample size of 20 mothers and their associated health visitors was considered both sufficient for the purpose of exploring process and manageable in terms of the demands of data collection and analysis undertaken concurrently with the quasi-experimental evaluation. Recruitment began with the Starting Well health visitors; 'stakeholder' meetings were held in both locations in order to explain the purpose of the study, seek views about how the different aspects of the intervention could best be captured and seek volunteers for participation. These meetings were invaluable in shaping the conduct of the study and in confirming almost universal willingness to participate among the health visitors. A total of 14 of the 16 health visitors agreed to participate and select parental participants from their caseloads. Sampling of parents was 'purposive', including first-time and experienced mothers, mothers experiencing a range of emotional, physical and material needs, and mothers from an ethnic minority background. In order to capture ongoing service development, parents were recruited in two cohorts. Follow-up interviews were conducted with 13 of the sample of 20 mothers. Seven mothers could not be contacted or opted out of the second interviews for a variety of reasons. Health visitors were interviewed at least once at the same time points and some were visiting more than one of the sample parents. The following findings are based on a total of 59 interviews carried out during 2002 and 2003. An indication of interview content is given in Box 5 .

Ethical approval was obtained from the associated primary care trust ethics committee and the provisions of the Data Protection Act 1998 were adhered to. Particular attention was given to issues of confidentiality in data analysis and reporting. The data extracts below use numbers for individual health visitors (e.g. HV1) and mothers (e.g. M1), and indicate whether the first or second interview was used [e.g. HV1(1)].

All interviews were tape-recorded with the exception of two conducted through an interpreter. In these two cases, notes were taken. Tapes were transcribed and analysis undertaken by both authors. The volume of material meant that a purely inductive approach to analysis was not feasible. Moreover, this would not

Box 5 Examples of interview questions

Health visitors

- Could you describe how the mother reacted to being offered Starting Well?

- Could you describe how you went about assessing the family's needs?

- Did you use a particular model or strategy that is part of Starting Well?

- How has your approach to this family and their needs developed over time?

Mothers

- When you first heard about it, what did you think Starting Well was trying to achieve?

- What are the biggest challenges you've faced in the past 12 weeks?

- What kinds of help has the health visitor given you over the past 12 weeks?

- How would you describe the relationship with your health visitor? How has it changed over time? 
have resonated with the interview approach, which had pursued particular practice and policy issues. Instead, a thematic approach focused on a number of different aspects of Starting Well, including how the programme was implemented, what the perceptions of the Starting Well model of health visiting were, and whether and how it conferred maternal and child benefit. In order to ensure rigour in the analysis process, the authors crosschecked emerging themes, compared their developing interpretations, checked the degree of congruence between health visitor and mother statements about process and revisited the transcripts for disconfirming evidence. The following selective findings highlight some of the key issues.

\section{Results}

\section{Processes of programme implementation: intensive visits}

As indicated above, a key element of the programme comprised intensive home visits in the early weeks of the child's life, followed by regular, less-frequent visits as the child developed. While the majority of health visitors were unable to visit antenatally, they were, without exception, able to provide the recommended number of visits to mothers entering the programme in its early phase. Most mothers, including those who already had children, appreciated this level of support in the first few weeks of their infant's life:

Just advice and anything I have not been sure of - it's been great to have HV2 coming out at the beginning, especially when I wasn't sure of some things like colic or her eczema just anything in general you want to ask about the baby ... HV2 has been there. [M3(1)13]

Health visitors also testified to the value of regular visits to the mothers:

I think, for families, it's been a huge success. The bits of feedback that we are getting now are very positive ... One [mother said] that she doesn't know how she would have survived without having this intensive input from the health visitor. Families are beginning to compare what the Starting Well intervention is compared with, maybe, friends or relatives that have not had Starting Well. [HV2(1)59]

However, the provision of intensive visits on a universal basis became impossible in one of the designated areas where changes in the way the project was implemented meant that Starting Well health visitors were required to take on heavier caseloads, and thus, to target the intensive visits to those most in need of support once the baby was a few weeks old:

I was talking to other health visitors the other day and it's become totally unworkable ... that you've created such a demand-you've raised the expectations at the beginning with a lot of the families and then, as your caseload rockets, you can't fulfil what you have promised. We all make sure that we do visit them quite intensively for the first $6-8$ weeks no matter what. That's where your relationship does get built up. [HV8(2)25]

The need to withdraw from families in order to prioritise and cope with workload pressures poses particular challenges for health visitors and mothers following a period of intensive visiting:

There's different phases in a relationship: There's the initial 'Well, I don't really know you, you don't know me' at the beginning. Then, the more often you go in, the more you build a rapport with people. They build up a trust in you and you have to be careful of how you go about getting through the next phase of 'Well, if you've got no concerns, I've got no concerns, there's not the same need for me to come in' bit. How do I do that without you feeling that I'm abandoning you? [HV6(2)8]

Of those mothers who subsequently experienced fewer than the planned visits, most were satisfied with phone contact in the event of any problems with their child. One or two who subsequently suffered a setback, one involving the return of depression, were unhappy at the reduction of intensive visits that they had found very supportive.

\section{Programme processes-building relationships over time}

All the study health visitors testified to the value of a relationship built over time that developed trust, and being located in the privacy of the home, facilitated an intimate knowledge of family problems and styles of parenting:

It's an intensive home-visiting programme, and on a first visit, you would only see so much and people wouldn't tell you. People tell you more in Starting Well because they get to know you a bit better. [HV5(1)28]

Some health visitors provided graphic examples of serious family problems and personal tragedies likely to impact on maternal mental health that were disclosed only after a number of weeks of visiting. This serves to highlight an important and unanticipated consequence of intensive visiting, namely its capacity to lead to the identification of higher levels of need and the attendant increase in workload for health visitors as they wrestled to provide appropriate support.

The importance of creating the right conditions for disclosure of problems and anxieties was confirmed by many of the mothers. Moreover, home visiting was compared favourably with clinic attendance by both mothers and health visitors: 
When you're up the health centre, you're shipped in and shipped back out; you're just a number. When she was coming out here, she was listening and actually paying attention to what [the child] was doing and his behaviour. [M10(2)13]

Disclosure is, of course, essential to equipping practitioners with better knowledge of the mother, thus providing a basis for relevant and person-centred support. However, the approach to provision of support was crucial to mothers' willingness to engage with information directed at improving or maintaining their own or their baby's health. The health visitors in the present study had received additional input on evidence-based practice, and had at their disposal a range of materials on infant health, maternal mental health and good parenting practice. Armed with these resources, the majority of practitioners adopted an approach that was 'empowering' in that they offered information and advice while emphasising that mothers could decide what they thought was best for their infant:

The ethos behind it is that you're working alongside the families in Starting Well. There's a recognition that you're not so prescriptive in the way you approach things, that you work in collaboration with the families. When you offer these visits it's offered visits, negotiated with families, not having to stick to a rigid pattern. [HV6(2)15]

Without exception, mothers identified this approach to their questions and concerns as helpful and supportive. One or two with prior experience of the health visiting service were pleasantly surprised at the non-intrusive ethos of this approach:

I just thought they [health visitors] were nosy people. When I had [older child] they were sort of looking about your house and 'Was it clean enough?' At first, when HV5 came in, I was apprehensive about her. I thought, 'Right, she is a bit snobby,' and I was going to be put through all this carry on again. But she was completely different and I got on good with her. [M7(1)22]

However, this facilitative approach was not universally adopted, and one mother was particularly resentful of the more authoritarian stance taken by her health visitor:

I think she interferes too much. She tells me not to do this and not to do that, and my oldest is 14 . The way she's going on, it's as if that's my first [baby], you know. I have already reared two up [children aged 14 and 12 years]. The way she goes on, it's as if you are not doing things right. [M8(1)21]

It is important to note that, in this particular case, the health visitor was concerned at the mother's hygiene practices, one of which had resulted in her infant experiencing more than one episode of ill health. The health visitor's directive approach eventually succeeded in removing what she perceived to be the main health hazard, but in the process, the mother felt alienated.
With this and one other exception, the majority of mothers responded positively to the support that was offered. This is not to say though that there were no differences of opinion about infant care. In several cases, health visitors described how lengthy discussions about the merits of breast-feeding, types of infant milk and later weaning eventually proved worthwhile in terms of the outcome for the infant. One mother reported this process:

I would say there is negotiation. Like the milk - I wanted to change because I thought he wasn't getting the benefit out of it and she sort of talked me round to saying, 'All right then, I'll not change him. I will persevere,' because she thought he was feeding enough. She won because it was right. [M7(1)39]

\section{Linking processes to programme benefits}

In general, health visitors found it easier to comment on programme benefits than the mothers, and were more likely than mothers to attribute causal significance to their work or to the project overall. Mothers' comments tended to be more circumspect, suggesting that they were unused to reflecting on the impact of services in a cause-andeffect way. In one or two cases, however, mothers reported their perception of a clear link between health visiting input, and maternal or infant benefit. It is noteworthy that the substance of these examples of 'benefits' were quite different from the outcomes traditionally associated with quantitative evaluations, such as increased immunisation uptake. Moreover, there was a strong correspondence between mother and health-visiting accounts of benefit. Three mothers directly attributed perceived developmental gains in their child to health-visiting input:

A lot of the key stages in his development might not have been picked up by me because I'm not trained in child development. So having somebody there that's trained in it and knows exactly what way to put things to children, what way you learn, what stage they learn at - that's what Starting Well helped me - so I don't think he would have been as good now if I hadn't had that help, I don't think I would of done as good a job. [M12(2)37]

Several mothers reported improvements in their mental health that they attributed to health visitor support. This support took a number of forms including the provision of 'listening visits', recommending a general practitioner consultation for assessment and medication, and monitoring the progress of mental health using the Edinburgh Post-Natal Depression Scale:

I mean, the last couple of months have been a whole lot better and I see life a wee bit different from right at the beginning. I'm like, 'Well, get up and do something,' and I do feel as if [HV4] has had a lot to do with that you know? [M6(2)55]

However, the most overwhelmingly dominant and clear message emerging from the mother interviews 
was the perception that the programme offered enhanced levels of support. Statements to this effect were made in detail by virtually every participant regardless of need and background across both cohorts, and in both first and second interviews. Favourable comparisons were made not only with previous personal experience with health visitors, but also with friends and family members who were receiving the existing generic service elsewhere in the city.

When mothers' statements about their perception of 'support' were explored in more depth, it was possible to identify a number of interactional processes that conferred five key benefits for mothers and their infants. These benefits were increased confidence in carrying out infant care and exploiting community resources, reduced anxiety in relation to infant care needs such as feeding, an increase in knowledge and in their sense of personal competence in parenting practices, reduced isolation, and the experience of advocacy for those experiencing housing, financial or family problems. The interactional processes that resulted in these forms of perceived support were quite complex in some cases. They involved a variety of methods of providing information, modelling mother/infant communication, cautious and tactful questioning of maternal decisionmaking, encouragement of successful parenting practice, and praising achievement.

Some examples of methods of information-giving have been included above, but it is worth emphasising the value that mothers attached to approaches that were non-judgmental and conferred legitimacy upon individual choice regarding infant care:

I felt really, really comfortable with HV9 because she never judged. She never forced you into doing something. She always gave you the option. She would give advice, but she said, 'It's up to you whatever you want to do.' [M14(2)38]

Questioning of maternal decision-making in a non-threatening way also yielded positive benefits for child health. HV1 described the process at an antenatal visit:

She was saying that she was not going to breast-feed, because her mum said she can't because she's not got a very healthy diet. Now you are conscious of not wanting to slander her mother, and I said, 'OK, can I just ask what kind of diet do you have just now?' and she said, 'Ordinary,' and I said, 'Well, do you think you are healthy now?' 'Yes,' and 'Is the baby growing?' 'Yes' 'And is the doctor saying you are fine?' and I said, 'Well, are you feeding your baby?' and she said, 'Yes,' and I said, 'Is there a reason why you couldn't breast-feed?' She said, 'Hmm, well maybe not,' and I said, 'You know, your nutrition is adequate, you know, and it would be the same, just the exact same diet, you don't have to change your diet or anything,' and she was taking all this on board and she is still to this day breast-feeding. [HV1(1)7]
HV2 demonstrated a number of interactional strategies in the following exchange and exemplified how an understanding of social networks, the building of confidence, provision of support and psychological well-being are interconnected:

HV2: She had to go hospital, and that was quite a setback for her, so a lot of the work has been around supporting her and building her confidence back up again, and making sure that she was physically fit to cope with the demands of motherhood, so I think there has been quite a good psychological support.

Interviewer: How do you go about doing that?

HV2: By encouraging her to talk about her experience, backing up what's she's saying and reinforcing that she is getting better, she is getting stronger, her anxiety levels are something that, over time, will reduce, and encouraging her to use other supports within the community where possible. [HV2(1)30-31]

These processes appeared to depend for their success on a sound knowledge of the mother and her social situation, careful timing, and sometimes, a sequence of visits to reinforce key messages about infant health in a non-judgmental way:

We've been doing Triple P, and I've been going over the tip sheets with her. She was shouting, and the wee fellow and her elder child was off school and she was shouting at her, and it wasn't positive, so we discussed that; about lowering your voice, trying to speak gently and all the other issues we'd discussed before, and she's taken that on board, but it's just a drip-drip. [HV5(1)19]

\section{Discussion}

The present paper aims to illuminate the Starting Well demonstration project model of health visiting in order to identify how the process of intensive visiting contributed to maternal perceptions of support. It can be argued that maternal perceptions of being supported and actions taken in response to health-visiting interventions can be taken as indicators of a potential to achieve health and developmental gain. As argued above, the way in which these interventions are accomplished within practitioner/family interactions has not been well explicated in previous studies and the present qualitative study has made progress in addressing this lack of evidence.

The medium for the process of supporting the study mothers was the schedule of intensive visits. What the Starting Well model has confirmed, like other studies in the field, is the substantial value of more intensive health visiting for those in most need (Elkan et al. 2000). The full scale and range of family needs among the participants were not usually disclosed until a relationship of trust had been built up, and many of the study health 
visitors acknowledged that, as new needs were uncovered, work with certain families intensified. This carries an important message for the way in which targeting of individual visits is managed. Targeting too early in the health visitor/parent relationship could result in failure to identify and subsequently address healthcare need. Therefore, there is a considerable challenge for practitioners in making judgements about targeting visits and interventions. There is a concomitant difficulty for managers, who are required to demonstrate a cost-efficient model of service delivery. This is especially the case because tools such as vulnerability scales have been shown to be unreliable (Appleton 1997). It is incumbent on those involved in setting the strategic direction for the health-visiting services to recognise the value of flexibility and the use of professional judgement in determining visit frequency. However, senior managers may not have sympathy with this view unless there is more robust evidence of the way in which skilled targeting at the individual level promotes the identification of, and response to, maternal and infant need.

The present study echoes the findings of other studies that a person-centred and non-directive approach to providing support is more likely to secure mothers' engagement with activities that maintain or improve family health (Heritage \& Sefi 1992, Kendall 1993, Bryans 2005). The negative impact of the one reported episode of a directive approach [M8(1)21 above] has also been reported elsewhere (Elkan et al. 2000). Although this represents a tiny minority of the participants included in the present study, it raises a key question about how an empowering approach can be adapted for working with mothers who choose not to engage with recommended best practice in the care of their infants. The theoretical underpinning of the home-support programmes have included 'self-efficacy' as a precursor to behaviour change (Olds et al. 1998). However, there is a lack of theory on approaches that are acceptable and non-intrusive in situations where practitioners perceive there to be health risk. As health visitors are undoubtedly addressing this issue on a regular basis, it is an aspect of practice that requires more systematic and critical scrutiny. Unfortunately, the present study was unable to further illuminate this issue since a limitation of volunteer samples is that participating mothers are likely to comprise a more-motivated group.

A key finding of the study was the mothers' perception of a diffuse sense of enhanced support. This was foundational to a number of important benefits. 'Support' is a multifaceted concept, and little evidence was found in the literature of its components and how they contribute to maternal and infant well-being. While the present study identified five core benefits of enhanced support and linked these with some of the interactional strategies used by health visitors, it did not provide the opportunity to explore in depth how underpinning theory informed these processes. It may be that the health visitors in the study were drawing on theory in their work as there were references to Neuman's model of health-visiting practice (Lowry \& Martin 2004). Interview data also demonstrated that they were 'ecologically aware' in terms of their understanding of the potentially positive or negative impact of both the wider and the home and family environment. However, the extent to which they consciously related their interactions to ecological or other theories was not pursued in the present study.

In discussing the documentation of programme success, one health visitor commented that, while traditional recording of infant feeding and weighing is important, of equal significance are the changes in mothers' attitudes and perceptions over time. Such indicators of programme benefits have been relatively neglected in much research in this field, and the present study demonstrates that they are arguably as or more important than dental registrations or minor improvements in immunisation rates. A more-focused investigation of the link between the theory, content and style of interaction and perceived benefit may offer health visitors and other health and social care practitioners a means of providing more robust evidence of the way in which some of the 'softer' process aspects of practice confer benefit. Such evidence would be invaluable for practitioner education, professional development and better-informed planning of health-visiting services.

\section{Acknowledgements}

The authors acknowledge with gratitude the funding that they received from the Scottish Executive Health Department. The views expressed in this paper do not necessarily reflect the views of the funding body. We would like to express our gratitude to Dr Alison Bryans and Linda Wallis for commenting on a draft of this paper, and to two anonymous referees for their constructive feedback.

\section{References}

Appleton J.V. (1997) Establishing the validity and reliability of clinical practice guidelines used to identify families requiring increased health visitor support. Public Health 111, 107-113.

Armstrong K.L., Fraser J.A., Dadds M.R. \& Morris J. (1999) A randomised, controlled trial of nurse home visiting to vulnerable families with newborns. Journal of Paediatrics and Child Health 35, 237-244.

Brooks-Gunn J. \& Duncan G.J. (1997) The effects of poverty on children. The Future of Children 7 (2), 55-71.

Bryans A. (2005) At home with clients: a study of health visiting expertise. Community Practitioner 78 (10), 358-362. 
Chalmers K.I. \& Luker K.A. (1991) The development of the health visitor-client relationship. Scandinavian Journal of Caring Sciences 5 (1), 33-41.

Ciliska D., Hayward S., Thomas H., et al. (1996) A systematic overview of the effectiveness of home visiting as a delivery strategy for public health nursing interventions. Canadian Journal of Public Health 87 (3), 193-198.

Cowley S. (1995) In health visiting a routine visit is one that has passed. Journal of Advanced Nursing 22, 276-284.

Department for Education and Skills (2003) Every Child Matters. Cm 5860. Department for Education and Skills, London.

Elkan R., Kendrick D., Hewitt M., et al. (2000) The effectiveness of domiciliary health visiting: a systematic review of international studies and a selective review of the British literature. Health Technology Assessment 4 (13), 1-339.

Glasgow Healthy City Partnership (1999) Starting Well Health Demonstration Project Proposal. Glasgow Healthy City Partnership, Glasgow.

Gomby D.S., Larson C.S., Lewit E.M. \& Behrman R.E. (1993) Home visiting: analysis and recommendations. The Future of Children 3 (3), 6-22.

Gomby D.S., Culross P.L. \& Behrman R.E. (1999) Home visiting: recent program evaluations - analysis and recommendations. The Future of Children 9 (1), 4-26.

Graham H. \& Power C. (2004) Childhood disadvantage and health inequalities: a framework for policy based on lifecourse research. Child: Care, Health and Development 30 (6), 671-678.

Heritage J. \& Sefi S. (1992) Dilemmas of advice: aspects of the delivery and reception of advice in interactions between health visitors and first-time mothers. In: J. Heritage \& J.C. Drew (Eds) Talk at Work, pp. 359-417. Cambridge University Press, Cambridge.

Jack S.M., DiCenso A. \& Lohfeld L. (2002) A theory of maternal engagement with public health nurses and family visitors. Journal of Advanced Nursing 49 (2), 182-190.

Kamerman S.B. \& Kahn A.J. (1993) Home health visiting in Europe. The Future of Children 3 (3), 39-52.

Kendall S. (1993) Do health visitors promote client participation? An analysis of the health visitor-client interaction. Journal of Clinical Nursing 2, 103-109.

Kitzman H., Olds D.L., Henderson C.R., et al. (1997) Effect of prenatal and infancy home visitation by nurses on pregnancy outcomes, childhood injuries, and repeated childbearing. A randomised controlled trial. Journal of the American Medical Association 278 (8), 644-652.

Leggat S.G. (2004) Healthy children, healthy country: the use of governing instruments in shifting the policy paradigm. [WWW document.] URL http://www.anzhealthpolicy.com/content/ $1 / 1 / 4$

Lowry L.W. \& Martin K.S. (2004) Organising frameworks applied to community-oriented nursing. In: M. Stanhope \&
J. Lancaster (Eds) Community and Public Health Nursing, 6th edn, pp. 194-219. Mosby, St Louis, MO.

Mackenbach J.P. \& Stronks K. (2004) The development of a strategy for tackling health inequalities in the Netherlands. [WWW document.] URL http://www.equityhealthj.com/content/ $3 / 1.11$

Mckenzie M., Shute J., Berzins K. \& Judge K. (2004) The Independent Evaluation of 'Starting Well': Final Report. Health Promotion Policy Unit, University of Glasgow, Glasgow.

McNaughton D.B. (2004) Nurse home visits to maternal-child clients: a review of intervention research. Public Health Nursing 21 (3), 207-219.

Olds D.L., Henderson C.R., Kitzman H., et al. (1998) Prenatal and infancy home visitation by nurses: a program of research. In: C. Rovee-Collier, L.P. Lipsitt \& H. Hayne (Eds) Advances in Infancy Research, Vol. 12, pp. 79-130. Ablex Publishing, Stamford, CT.

Olds D.L., Henderson C.R., Kitzman H.J., Eckenrode J.J., Cole R.E. \& Tatelbaum R.C. (1999) Prenatal and infancy home visitation by nurses: recent findings. The Future of Children 9 (1), 44-65.

Olds D.L. \& Kitzman H. (1993) Review of research on home visiting for pregnant women and parents of young children. The Future of Children 3 (3), 53-92.

Olds D.L., Kitzman H., Cole R., et al. (2004) Effects of homevisiting on maternal life course and child development: age 6 follow-up results of a randomised trial. Pediatrics 114 (6), 1550-1559.

Powell D.R. (1993) Inside home visiting programs. The Future of Children 3 (3), 23-38.

Ramey C.T. \& Ramey S.L. (1993) Home visiting programs and the health and development of young children. The Future of Children 3 (3), 129-139.

Sanders M.R. \& Woolley M.L. (2005) The relationship between maternal self-efficacy and parenting practices: implications for parent training. Child: Care, Health and Development 31 (1), 65-73.

Scottish Office Department of Health (1999) Towards a Healthier Scotland. Cm 4269. The Stationery Office, Edinburgh.

Shute J. \& Judge K. (2005) Evaluating 'Starting Well', the Scottish national demonstration project for child health: outcomes at six months. Journal of Primary Prevention 26 (3), 221-240.

St Pierre R.G. \& Layzer J.I. (1999) Using home visits for multiple purposes: the comprehensive child development programme. The Future of Children 9 (1), 134-151.

Sweet M.A. \& Appelbaum M.I. (2004) Is home visiting an effective strategy? A meta-analytic review of home visiting programs for families with young children. Child Development 75 (5), 1435-1456.

Vimpani G.V. (2002) Sure Start: reflections from Down Under. [Editorial.] Child: Care, Health and Development 28 (4), 281287. 